\title{
Validation of Pleiades Tri-Stereo DSM in Urban Areas
}

\author{
Emmanouil Panagiotakis ${ }^{1}$, Nektarios Chrysoulakis ${ }^{1}{ }^{(\mathbb{D}}$, Vasiliki Charalampopoulou ${ }^{2}$ and \\ Dimitris Poursanidis $1, *$ (D) \\ 1 Foundation for Research and Technology, Institute of Applied and Computational Mathematics, \\ Remote Sensing Laboratory, 70013 Heraklion, Greece; panagiotakisman@iacm.forth.gr (E.P.); \\ zedd2@iacm.forth.gr (N.C.) \\ 2 Geosystems Hellas S.A., 14452 Athens, Greece; b.charalampopoulou@geosystems-hellas.gr \\ * Correspondence: dpoursanidis@iacm.forth.gr; Tel.: +30-2810391774
}

Received: 4 January 2018; Accepted: 14 March 2018; Published: 15 March 2018

\begin{abstract}
We present an accurate digital surface model (DSM) derived from high-resolution Pleiades-1B $0.5 \mathrm{~m}$ panchromatic tri-stereo images, covering an area of $400 \mathrm{~km}^{2}$ over the Athens Metropolitan Area. Remote sensing and photogrammetry tools were applied, resulting in a $1 \mathrm{~m} \times 1 \mathrm{~m}$ posting DSM over the study area. The accuracy of the produced DSM was evaluated against measured elevations by a differential Global Positioning System (d-GPS) and a reference DSM provided by the National Cadaster and Mapping Agency S.A. Different combinations of stereo and tri-stereo images were used and tested on the quality of the produced DSM. Results revealed that the DSM produced by the tri-stereo analysis has a root mean square error (RMSE) of $1.17 \mathrm{~m}$ in elevation, which lies within the best reported in the literature. On the other hand, DSMs derived by standard analysis of stereo-pairs from the same sensor were found to perform worse. Line profile data showed similar patterns between the reference and produced DSM. Pleiades tri-stereo high-quality DSM products have the necessary accuracy to support applications in the domains of urban planning, including climate change mitigation and adaptation, hydrological modelling, and natural hazards, being an important input for simulation models and morphological analysis at local scales.
\end{abstract}

Keywords: tri-stereo; DSM; validation; urban surface morphology; line profile

\section{Introduction}

Satellite remote sensing (optical and synthetic aperture radar (SAR)) and airborne Light Detection and Ranging (LiDAR) technologies have been exploited for their capabilities on the production of large area high resolution DSM applied in urban studies [1-5], hydrological modelling [6], and natural hazards [7-9]. Both technologies have their limitations and advantages [6] as open access datasets did not provide the required detailed information for studies at local scales [10]. The first stereoscopic images that allowed the extraction of DSM over large areas were provided by SPOT in 1986 [11]. Since then, several very high resolution (VHR) satellites with stereo and tri-stereo capabilities have been launched during the last decade based on the demand of higher accuracy and large area coverage for DSM production (Table 1). Among them, the Pleiades-1 mission has attracted attention due to its unique tri-stereo image acquisition providing almost simultaneous images from three different views ( $\mathrm{fb}=$ forward-backward, $\mathrm{fn}=$ forward-nadir, Figure 1 ) for the same area, with a stereo angle varying from $\sim 6^{\circ}$ to $\sim 28^{\circ}$ with the same spatial resolution. This configuration, along with the use of the near-nadir image, allows a better retrieval of heights over terrains where the performance of classic photogrammetry with forward-backward looking only stereo pairs is limited [12]. Poli et al. [13] examined the capability of Pleiades-1A for DSM extraction over the Trento test field. By using 15 control points extracted by a LiDAR-based DSM, they achieved an RMSEz of 0.75, while Perko et al. [14] following a similar approach over Innsbruck city, Austria (a direct comparison of the produced DSM over the city vs. a LiDAR-based 
DSM) achieved a RMSEz of $2.4 \mathrm{~m}$. Bagnardi et al. [7] produced a DSM using $1 \mathrm{~m}$ Pleiades-1A imagery in order to calculate lava flow volume after the eruption of the Fogo Volcano in Cape Verde in comparison to a pre-eruption satellite-based SAR DSM from TanDEM-X. Berthier et al. [15], by using Pleiades, derived digital elevation models (DEMs) of glaciers. They noticed changes in the estimated elevation DEMs with a vertical precision at $\pm 1 \mathrm{~m}$ and $\pm 0.5 \mathrm{~m}$ on the flat glacier tongues ( $1 \sigma$ confidence level). The Pleiades-1 (1A and 1B) mission consists of a constellation of two satellites for VHR panchromatic (PA) and multispectral (MS) optical observations of the Earth's surface and is scheduled to continue for several years [16]. The tri-stereo (or multistereo) acquisition mode is set to become a common feature in future satellite missions.

Table 1. VHR satellites with stereo and tri-stereo capabilities.

\begin{tabular}{|c|c|c|c|c|}
\hline Satellite & Spatial Resolution (Panchromatic) & Stereo & Tristereo & Temporal Resolution \\
\hline Quickbird & $0.61 \mathrm{~m}$ & $\mathrm{y}$ & $\mathrm{n}$ & 1 to 3.5 days off-nadir \\
\hline Worldview-1 & $0.46 \mathrm{~m}$ & $\mathrm{y}$ & $\mathrm{n}$ & 5.9 days off nadir \\
\hline Worldview-2 & $0.46 \mathrm{~m}$ & $\mathrm{y}$ & $\mathrm{n}$ & 3.7 off nadir \\
\hline OrbView-3 & $1 \mathrm{~m}$ & $\mathrm{y}$ & $\mathrm{n}$ & 3 off nadir \\
\hline SPOT-6 \& SPOT-7 & $1.5 \mathrm{~m}$ & $\mathrm{y}$ & $\mathrm{n}$ & 1 day off nadir \\
\hline Resurs-DK1 & $0.8 \mathrm{~m}$ & $\mathrm{y}$ & $\mathrm{n}$ & 6 days off nadir \\
\hline $\mathrm{ZY}-3 \mathrm{~A}$ & $2.1 \mathrm{~m}$ Nadir/3.5 m Forward-Backward & $\mathrm{y}$ & $\mathrm{y}$ & 5 days off nadir \\
\hline IRS Cartosat-1 & $2.5 \mathrm{~m}$ & $\mathrm{y}$ & $\mathrm{n}$ & 5 days off nadir \\
\hline IRS Cartosat-2 & $1 \mathrm{~m}$ & $\mathrm{y}$ & $\mathrm{n}$ & 4 days off-nadir \\
\hline
\end{tabular}

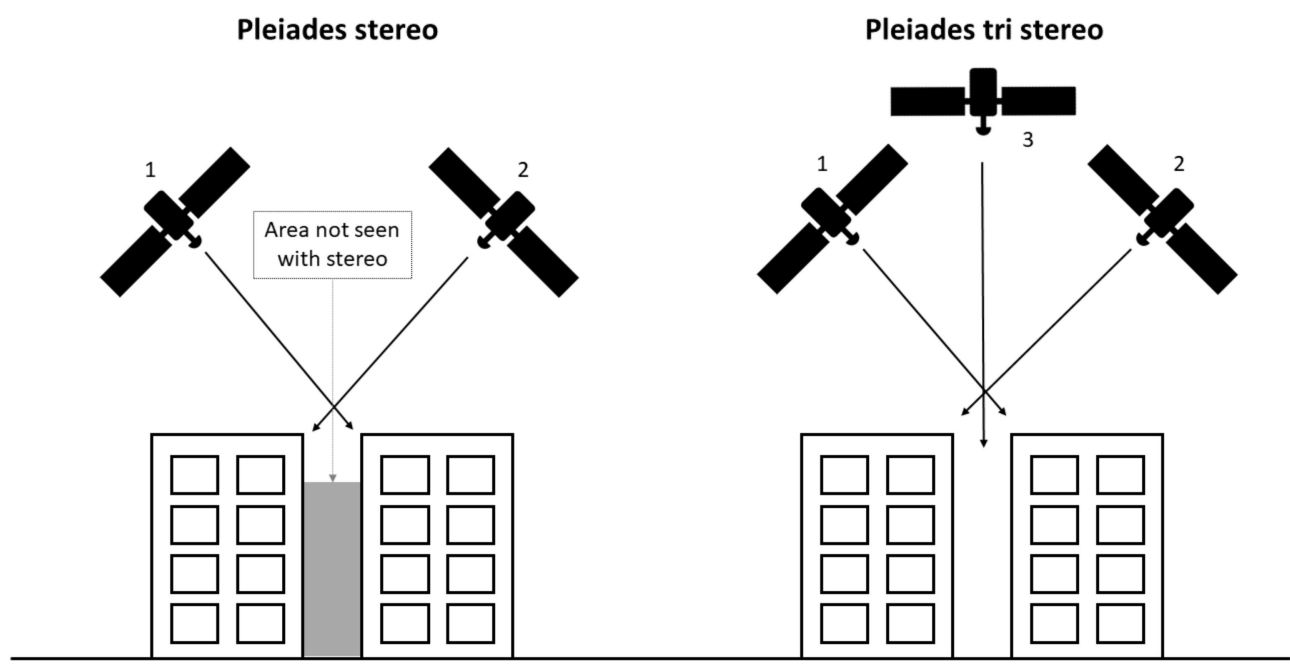

Figure 1. Stereo and tri-stereo views of the Pleiades-1 mission.

To this end, the objective of the present study is to exploit the potential of the DSM production over large urban areas, such as the Athens Metropolitan Area in Greece, using Pleiades-1 stereo and tri-stereo images. We will compare the results between the two approaches and evaluate the results using the official VHR DSM from the National Cadaster and Mapping Agency S.A. as a reference, measured point-based elevation data with D-GPS, due to the absence of LiDAR-based DSM, along with profile lines. 


\section{Materials and Methods}

\subsection{Study Area}

The study area is the central part of Athens Metropolitan area, covering $\sim 350 \mathrm{~km}^{2}$ in a dense cityscape surrounded by two mountainous massifs; Hymettus on the southeast and Aigaleo (Poikilon Oros) on the west-northwest side of Athens (Figure 2). Athens is the capital and largest city of Greece, dominating the Attica region. The central part of the area is characterized by a low/moderate relief with an average elevation of $400 \mathrm{~m}$ in the urban area.

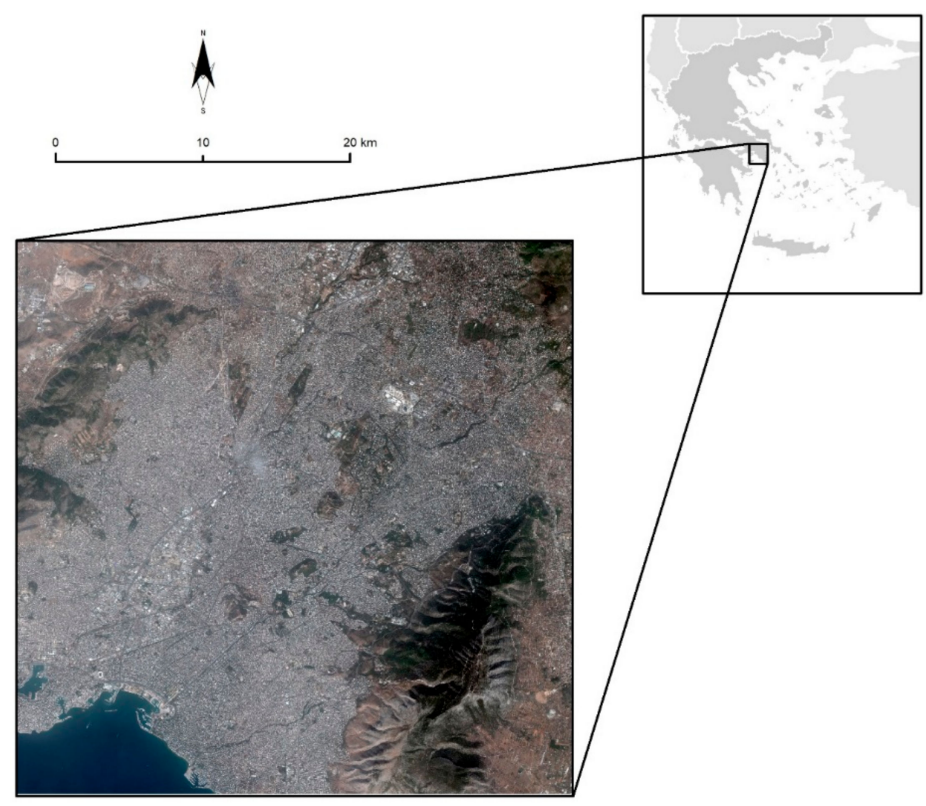

Figure 2. The study area in Athens by Pleiades 1B multispectral imagery.

\subsection{Data Processing and Analysis}

The first satellite, Pleiades-1A, was launched in December 2011, while the second, Pleiades-1B, was launched in December 2012. Both satellites, part of the French-Italian Optical and Radar Federated Earth Observation program for civilian and defense uses, orbit in sun-synchronous tracks with $98.2^{\circ}$ inclination and an offset of $180^{\circ}$ from each other, which allows a minimum revisit time of $24 \mathrm{~h}$. The PA and MS images are acquired simultaneously at a nominal resolution of $0.7 \mathrm{~m}$ and $2.8 \mathrm{~m}$, respectively [16]. Level-1B Pleiades cloud-free tri-stereo images acquired at 16 October 2016 (Table 2) have been processed using the Automatic Terrain Extraction with Dense Point Matching (eATE) of ERDAS IMAGINE Photogrammetry (Hexagon Geospatial, Atlanta, GA, USA). Orbital pushbroom has been selected as the geometric model with a classic point measurement tool for GCP preparations (Figure 3). After the preparation of the GCPs, block triangulation has been used to check the quality of the GCPs. Next, the eATE process is activated. At this stage, the output spatial resolution, the interpolation method and the smoothing factor of the DSM are defined. The set of the three panchromatic images have been visually inspected for radiometric inconsistencies due to operational aspects of image acquisition. Usually, such anomalies appear only in one image from a stereo pair or a tri-stereo acquisition set due to the presence of reflective surfaces (e.g., metal roofs, water masses causing sun glint), in combination with the imaging incidence angle [13]. None of these effects were observed in the present set of Pleiades images. A final set of ten GCPs has been extracted from the official orthorectified imagery basemap platform provided by the National Cadaster and Mapping Agency S.A., while the respected elevation has been extracted by the official DSM of the same area (Figure 4). 


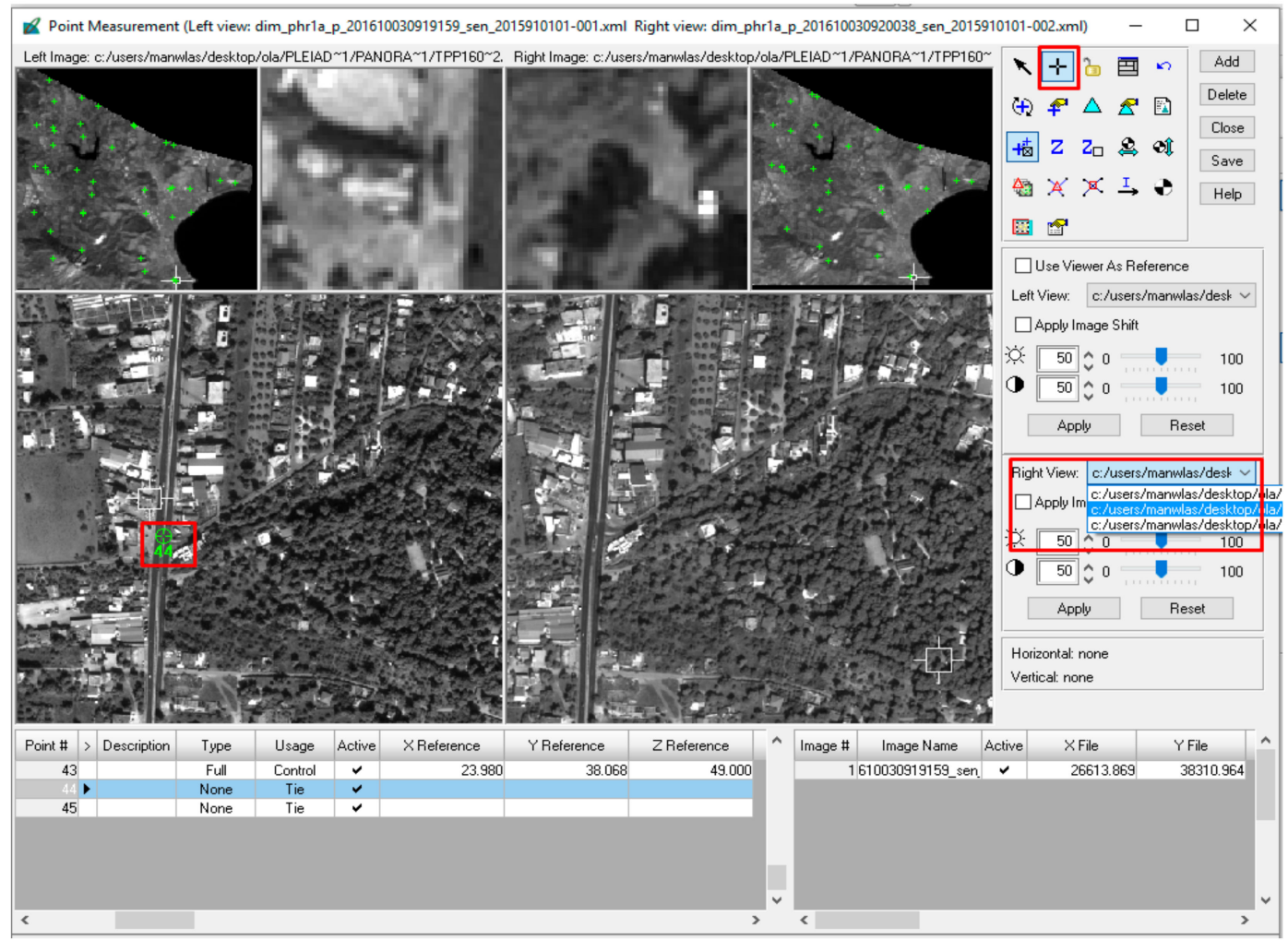

Figure 3. View of the ERDAS IMAGINE Photogrammetry for the GCP collection and preparation.

Table 2. The characteristics of the analyzed Pleiades tri-stereo acquisition.

\begin{tabular}{cccc}
\hline & Image 1 & Image 2 & Image 3 \\
\hline Along-track $\left(^{\circ}\right.$ ) & 13.84 & 3.17 & -7.81 \\
Across-track $\left(^{\circ}\right)$ & -4.01 & -3.45 & -2.86 \\
GSD (m) & $0.74 \times 0.74$ & $0.70 \times 0.71$ & $0.71 \times 0.71$ \\
Size (columns) & 39,501 & 40,000 & 40,000 \\
Size (rows) & 38,248 & 39,956 & 39,576 \\
Acquisition time & $9: 19: 36$ & $9: 19: 56$ & $9: 20: 16$ \\
\hline
\end{tabular}

Both the orthorectified images and DSM have been produced in 2010 and are used as reference data for the present study; data gaps shown in Figure 4 concern classified areas by the Hellenic Military Services. In the absence of LiDAR-based DSM, for the validation of the produced DSM, three different approaches have been selected and used: (a) 188 random check points with elevation data from the reference dataset in of more than $50 \mathrm{~m}$ distance from each other (avoiding spatial autocorrelation following a rule of thumb that each point has to be at a distance of 40 times the size of a pixel [17]); (b) four line profiles across different areas, including urban canyons, open spaces, highway, and buildings of different use; and (c) 26 in situ measured points across the project area using Trimble R-10 GNSS units (Sunnyvale, CA, USA) and system corrections via the country ground reference stations of the HEPOS network (Figure 4). These have been measured at pavements corners and on roof corners of buildings but also within street canyons. RMSE, a comprehensive statistic metric, has been selected as the evaluation metric of the accuracy of the produced DSM. Linear errors at $95 \%$ and $99 \%$ confidence intervals (CI) have been calculated from the RMSE. 


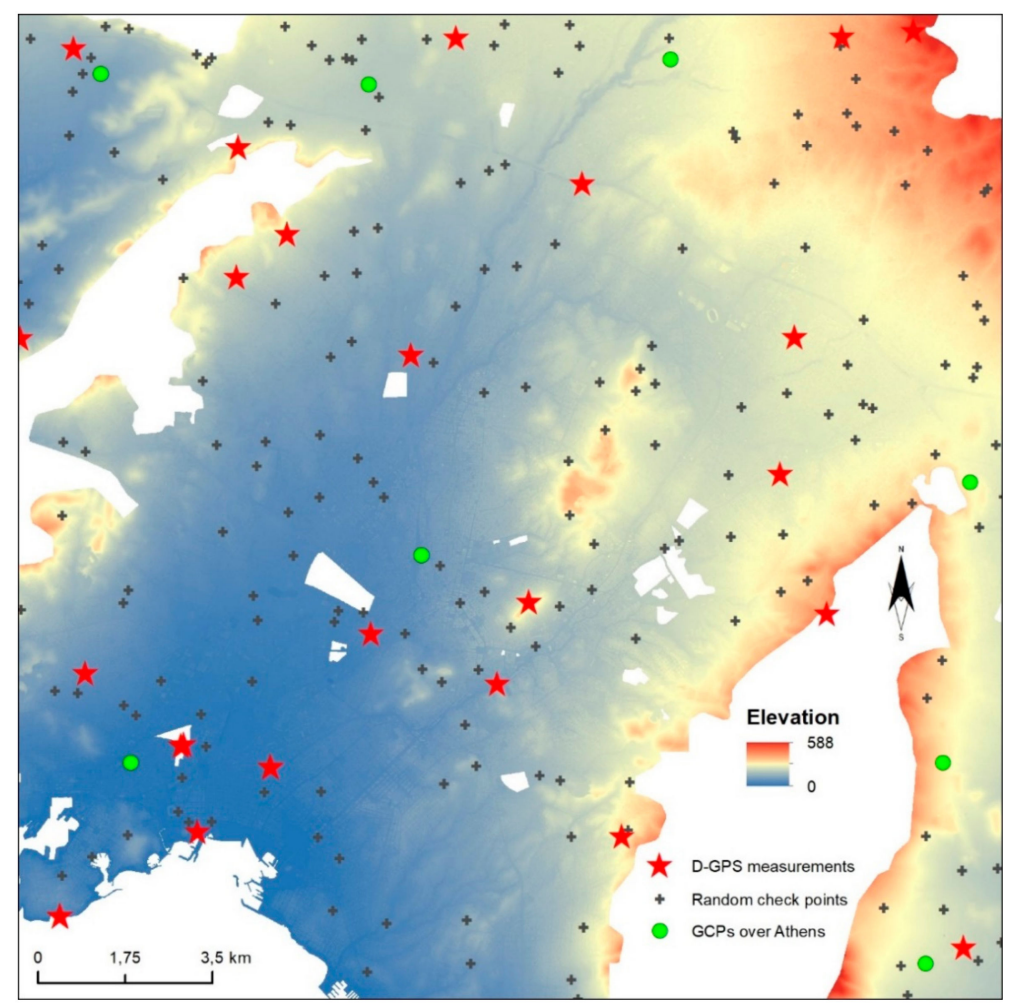

Figure 4. The project area with overlaid the reference DSM, the dataset of GCPs, the random check points, and the d-GPS measured data.

\section{Results and Discussion}

After the analysis of the tri-stereo image set of Pleiades-1B, the produced DSM with a spatial resolution of $1 \times 1 \mathrm{~m}$ show a detailed cityscape with some issues related to "noise and spikes" in comparison to the reference dataset (Figure 5). The majority of the "noise and spikes" issues appear on the road network or in streets with narrow canyons due to moving objects and shadow effects. We must underline that the produced DSM from Pleiades-1B has not been post-processed using any type of filtering for noise and artifact removal. Checking the produced DSM with d-GPS points, the RMSEz is at $1.8 \mathrm{~m}$. Tests on the stereo and tri-stereo DSM production from Pleiades shows that the tri-stereo has better performances in terms of RMSEz (tri-stereo $=1.17 \mathrm{~m}$, stereofb $=1.48 \mathrm{~m}$, stereofn $=1.64 \mathrm{~m}$ ). From the RMSE of the tri-stereo DSM, the LE95 is $2.29 \mathrm{~m}$ and LE99 is $3.02 \mathrm{~m}$, respectively. The RMSE is an aggregated measure of the vertical accuracy of the produced DSM. To assure its accuracy at local level, one method is to visualize how the difference ZPleiades-ZReference is distributed in space, hence, one may depict the magnitude of this difference around each checkpoint. Differences among ZPleiades-ZReference have been calculated (Figure 6). Pleiades DSM, as well as the reference DSM for the study area, show strong positive correlation. The results show strong correlation for the estimated elevation differences between the two DSMs, and observations corresponding to slope are much smaller, but still positively correlated (Figure 6). The scatter plot of the Pleiades DSM, as well as the reference DSM values, reflect this strong correlation (Figure 7). To check for the elevation-caused bias, we used a scatter plot of the Pleiades DSM vs. the reference DSM, in comparison with the elevation data from the reference DSM (Figure 8). The dataset shows that most of differences cluster around the mean difference (avg $=0.53$ ). While point-based accuracy is the standard tool for the assessment of a DSM, line profiles can provide a different view on the structure of a produced DSM when compared to a reference dataset $[18,19]$. In Figure 9, the elevation profiles from four line transects running across different urban features (Figure 10), are compared with elevation data from the reference and produced 
DSM. The profile lines obtained from the reference DSM are smoother in comparison with the extracted from the Pleiades-based DSM.

The higher elevation differences in steep heterogeneous areas within narrow urban canyons due to shadows or other terrain features, or over areas where moving objects exist (like the highway), pose a challenge for the DSM extraction, but also indicate the need for the correction of such errors using filters in a post-process analysis.

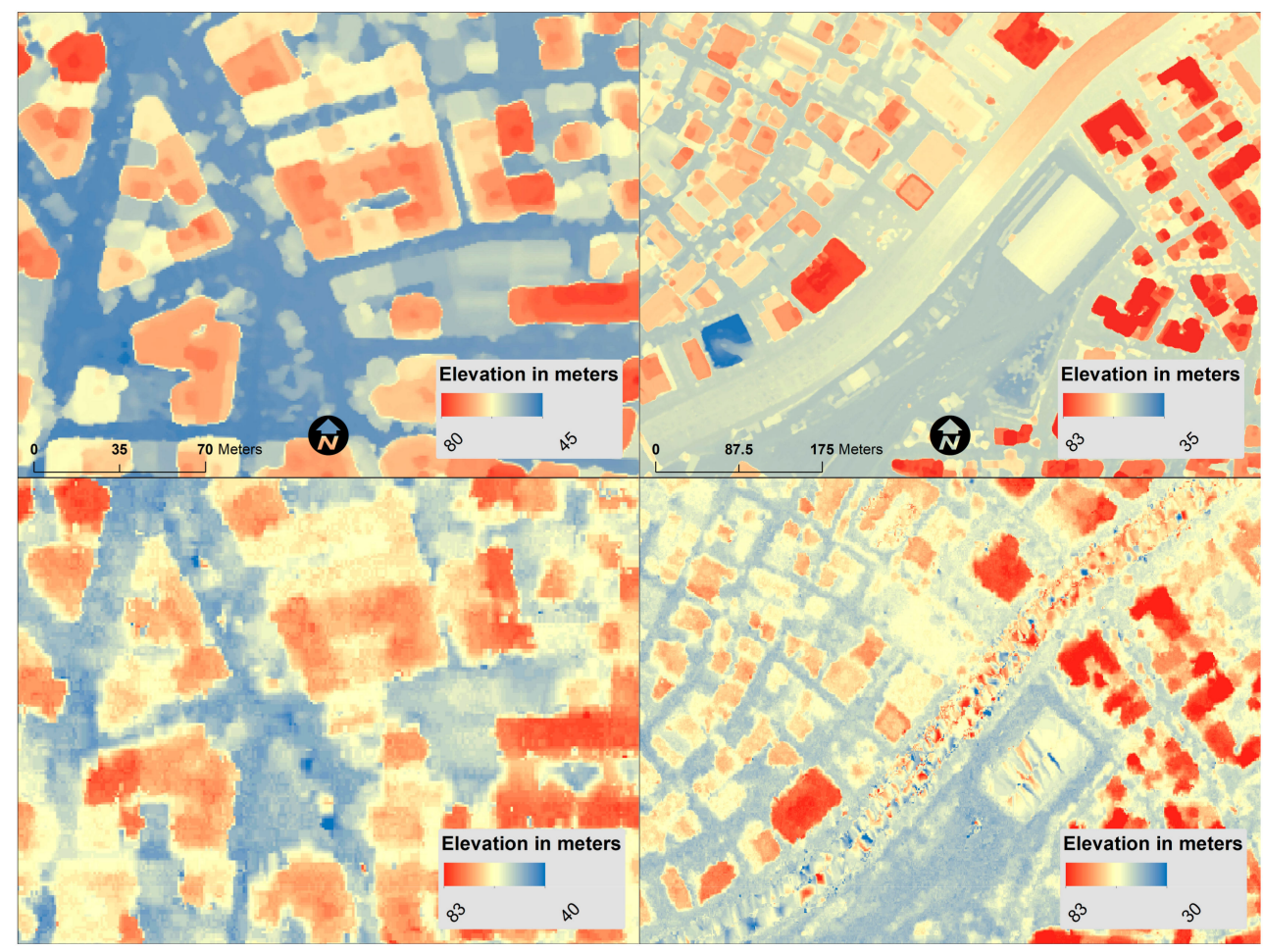

Figure 5. Details in the cityscape of Athens in the level of neighborhood from the reference dataset (above) and the produced DSM (below).

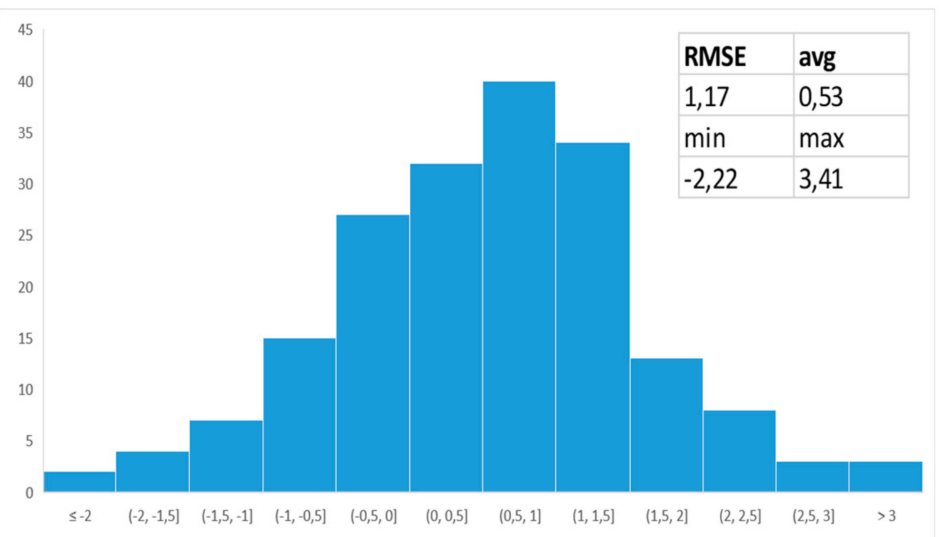

Figure 6. The probability distribution of error, the means correspond to biases (systematic effect) and the variances correspond to random effects; values are in meters. RMSE is at $1.17 \mathrm{~m}$.

The reference DSM is a post-processed dataset (break lines to correct edges and roads removing moving objects), smooth and ready-to-use in analysis, while the produced DSM from Pleiades has not been post-processed. Thus, spikes and artifacts that are visible at Figure 9 will be removed during a post-process analysis. 


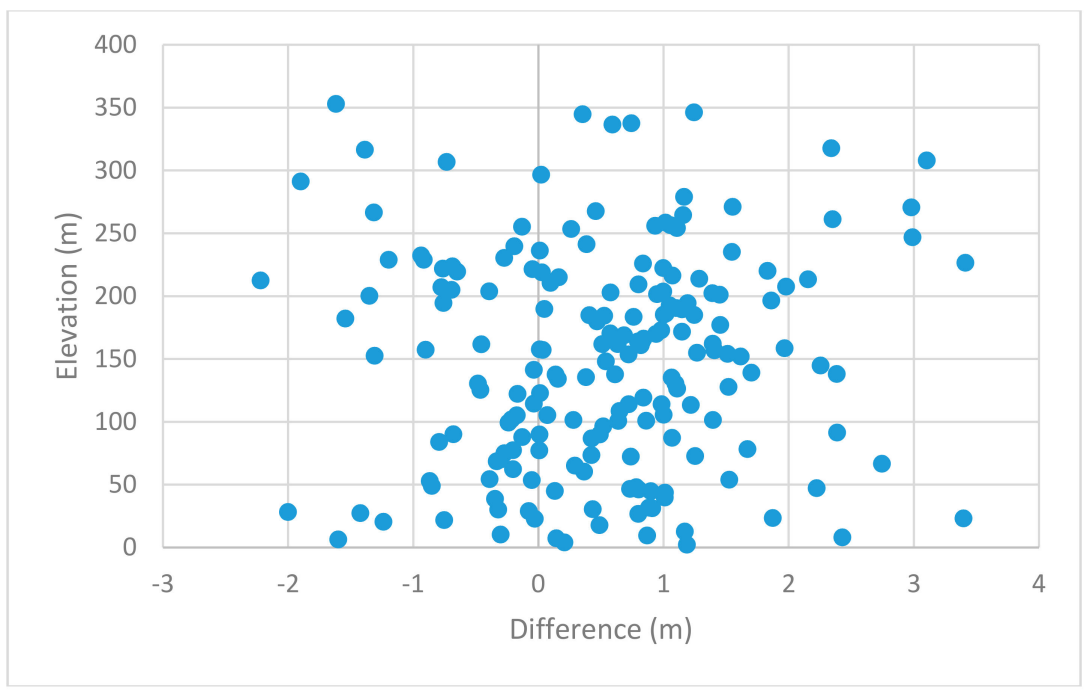

Figure 7. Scatter plot of Pleiades-reference DSM difference vs. elevation. No important bias is being observed.

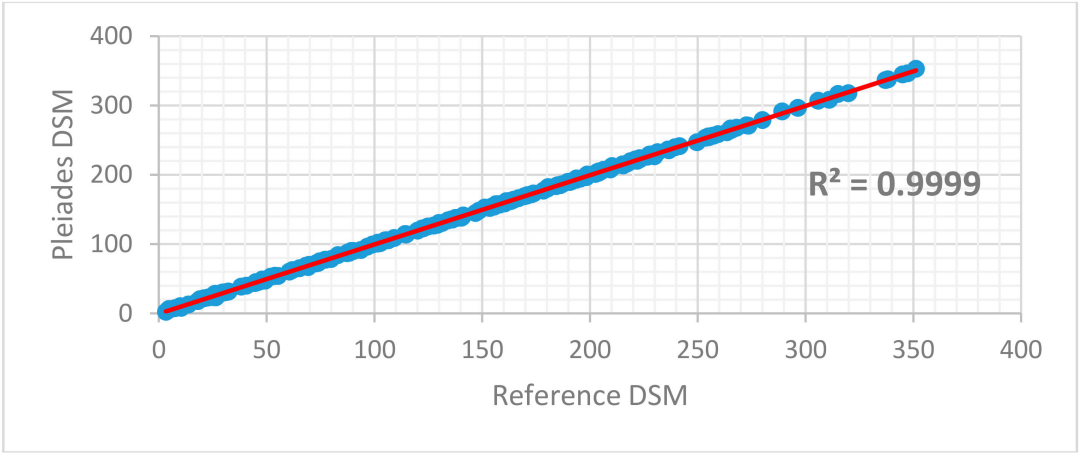

Figure 8. Scatter plot of Pleiades DSM vs. he reference DSM for the 188 random points.

Airborne LiDAR technology for DSM production provides unprecedented accuracy whilst the cost is quite high in comparison to the SRS methods. Moreover, it is spatially restricted over sensitive areas and the frequent updates of such datasets are very costly. SRS-based methods, such as that of the present work, can provide an automated method to extract high-resolution DSMs across the globe with a relatively low cost, high accuracy, and frequent temporal cover, whereas the spatial coverage is quite large and there are no restrictions on the spatial coverage [20]. The reference DSM has been produced by using stereo airborne cameras with a simultaneous image caption at elevations lower than that of the Pleiades $1 \mathrm{~B}$ satellite. The raw data have been captured at a resolution of $0.25 \mathrm{~m}$ and the final DSM has been delivered at $0.8 \mathrm{~m}$ including several post-processing steps for the removal of spikes and artefacts over road networks. All of the above correspond to a reference DSM dataset over the cityscape of Athens. The produced DSM presents more noise and elevation spikes, mainly over the road network, mainly caused by moving objects and shadows in narrow street canyons. Poli et al. [13], using Pleiades-1A, show similar results as the tri-stereo images did not include a real nadir acquisition, like the present study. The temporal resolution between the Pleiades 1B tri-stereo images according to the metadata is $40 \mathrm{~s}$ between each acquisition, sufficient time for changes over the same scene for moving objects. Whilst GCPs have a crucial role in the production and the quality of the DSM, the number used in each case study is related to the quality of the GCPs in terms of vertical and horizontal accuracy. The present study ends up with 10 GCPs over an area of $400 \mathrm{~km}^{2}$, resulting in a highly accurate DSM with an RMSE of $1.17 \mathrm{~m}$, among the highest reported so far. The number of the $10 \mathrm{GCPs}$ has been selected after initial tests over a larger dataset. By reducing the dataset's size, we observed that the RMSE does not change. 


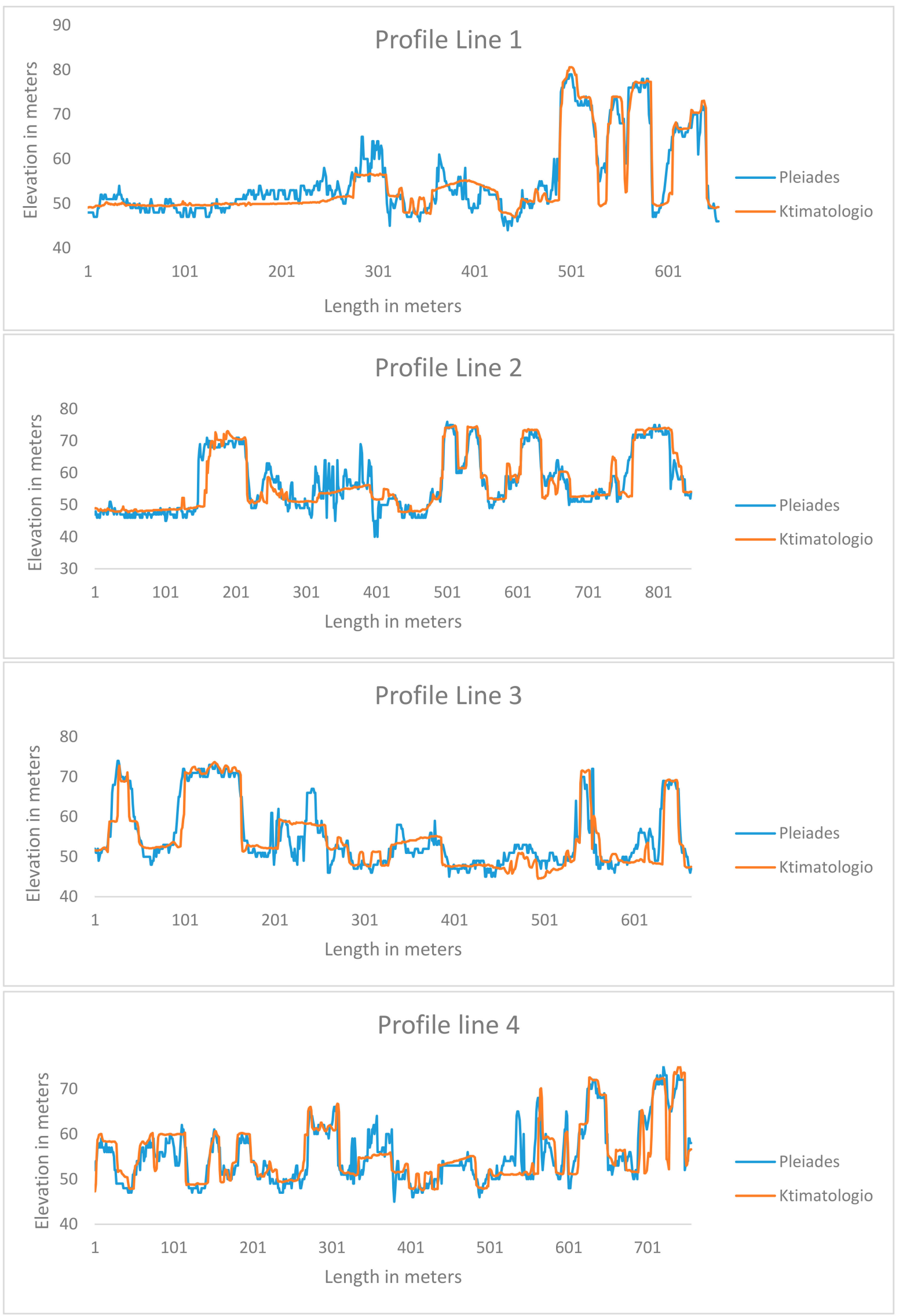

Figure 9. Line profiles with elevation data from Pleiades and Ktimatologio. 


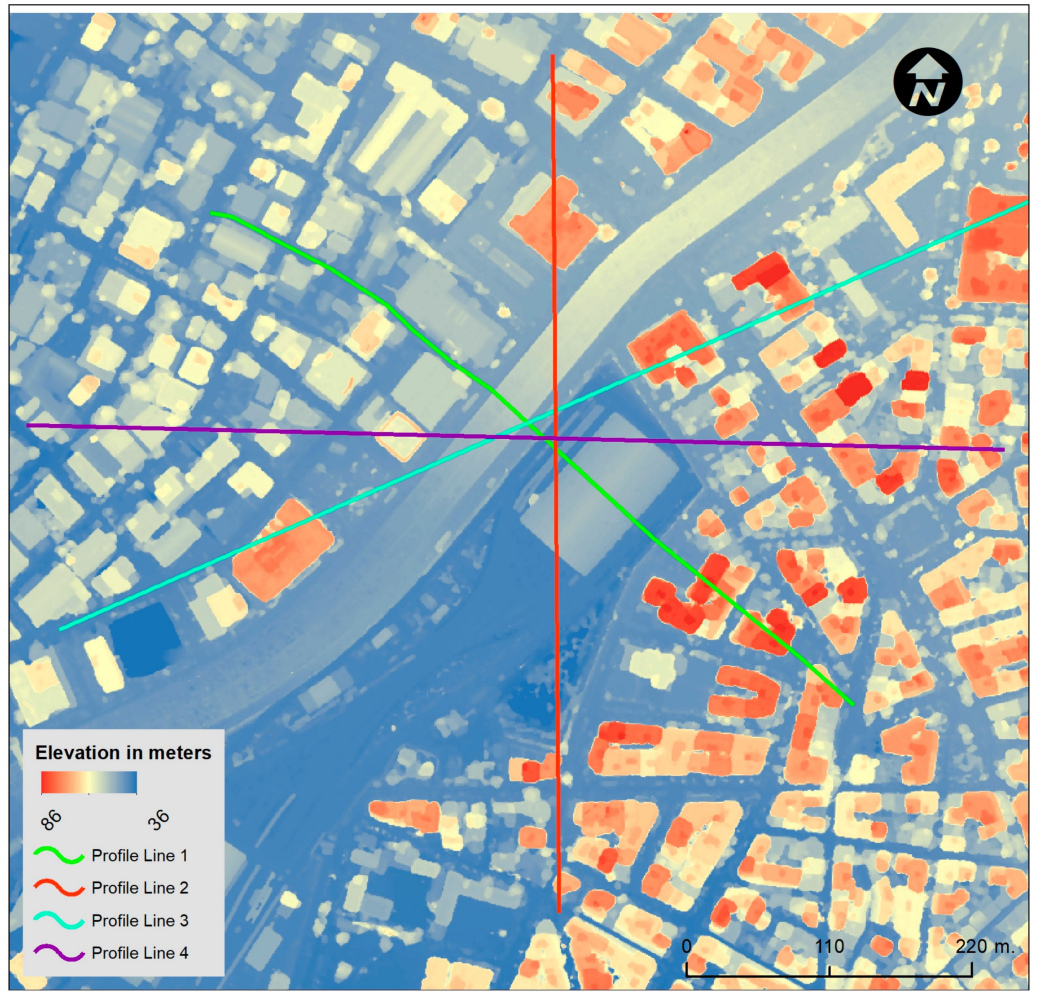

Figure 10. The profile lines above different urban features overlaid at the reference DSM.

DSMs are incorporated in the process of image classification in urban/rural areas, for a holistic approach of land use/cover with improved results [21], or a targeted image classification, as is the case of urban green vegetation [3], but also in the process of the extraction of buildings [22,23], which resulted in more accurate results. The incorporation of DSMs in mapping elements in urban environments can benefit the current research by improving the results by incorporating texture and shape information apart from the spectral information [24,25]. It is important to state that moving object detection over same dataset resulted in advanced datasets, which is important for studies in urban environments [26].

\section{Conclusions}

The goal of this work was to validate the high-resolution DSM produced by the analysis of Pleiades-1B over the Athens Metropolitan Area. Tri-stereo imagery analysis provided the best results in comparison to the standard analysis of stereo-pairs. Ten evenly-distributed GCPs across the study area have been used to produce the DSM, which reflect a sufficient number for the total area of 400 $\mathrm{km}^{2}$. Two independent reference datasets have been used to evaluate the final products: GCPs evenly distributed across the study areas and $\mathrm{z}$ values coming from a reference DSM, produced by aerial stereo images and measured points with D-GPS. The first dataset provided an RMSEz of $1.17 \mathrm{~m}$, which is among the lowest errors that have been presented so far while the second dataset provided a slightly higher RMSEz of 1.82. Line profile examination over the produced and the reference DSM indicated that noise and artifacts need to be removed by post-processing. The present study showed that the Pleiades constellation $(1 \mathrm{~A} / \mathrm{B})$ can provide the required terrain information over urban areas across the globe. Important is the case of megacities in areas that are under development (e.g., China, India) where by using applied remote sensing tools and methods DSM with high accuracy can be produced, covering large areas with no spatial restrictions, like in the case of airborne-based campaign data.

Acknowledgments: The authors are grateful to the EnCeladus Hellenic Supersite (http:/ / www.earthobservations. org/gsnl.php) for the Pleiades data provision. 
Author Contributions: All authors contribute equal to this work.

Conflicts of Interest: The authors declare no conflict of interest.

\section{References}

1. Krauss, T. Preprocessing of satellite data for urban object extraction. Int. Arch. Photogramm. Remote Sens. Spat. Inf. Sci. 2015, XL-3/W2, 115-120. [CrossRef]

2. Yong, X.; Ren, C.; Ma, P.; Ho, J.; Wang, W.; Ka-Lun Lau, K.; Lin, H.; Ng, E. Urban morphology detection and computation for urban climate research. Landsc. Urban Plan. 2017, 167, 212-224. [CrossRef]

3. Lefebvre, A.; Nabucet, J.; Corpetti, T.; Courty, N.; Hubert-Moy, L. Extraction of urban vegetation with Pleiades multiangular images. Remote Sens. Technol. Appl. Urban Environ. 2016, 10008, $100080 \mathrm{H}$.

4. De Vieilleville, F.; Ristorcelli, T.; Delvit, J.-M. DEM reconstruction using light field and bidirectional reflectance function from multi-view high resolution spatial images. Int. Arch. Photogramm. Remote Sens. Spat. Inf. Sci. 2016, XLI-B3, 503-509. [CrossRef]

5. Chrysoulakis, N.; Marconcini, M.; Gastellu-Etchegorry, J.P.; Grimmond, C.S.B.; Feigenwinter, C.; Lindberg, F.; Del Frate, F.; Klostermann, J.; Mitraka, Z.; Esch, T.; et al. Anthropogenic heat flux estimation from space: Results of the first phase of the URBANFLUXES project. Remote Sens. Technol. Appl. Urban Environ. 2016, $10008,100080 \mathrm{C}$.

6. Tsanis, I.K.; Seiradakis, K.D.; Daliakopoulos, I.N.; Grillakis, M.G.; Koutroulis, A.G. Assessment of GeoEye-1 stereo-pair-generated DEM in flood mapping of an ungauged basin. J. Hydroinf. 2014, 16, 1-18. [CrossRef]

7. Bagnardi, M.; González, P.J.; Hooper, A. High-resolution digital elevation model from tri-stereo Pleiades-1 satellite imagery for lava flow volume estimates at Fogo Volcano. Geophys. Res. Lett. 2016, 43, 6267-6275. [CrossRef]

8. Wang, R.; Zhang, S.; Pu, L.; Yang, J.; Yang, C.; Chen, J.; Guan, C.; Wang, Q.; Chen, D.; Fu, B.; et al. Gully Erosion Mapping and Monitoring at Multiple Scales Based on Multi-Source Remote Sensing Data of the Sancha River Catchment, Northeast China. ISPRS Int. J. Geo-Inf. 2016, 5, 200. [CrossRef]

9. Poli, D.; Caravaggi, I. 3D information extraction from stereo VHR imagery on large urban areas: Lessons learned. Nat. Hazards 2013, 68, 53-78. [CrossRef]

10. Chrysoulakis, N.; Abrams, M.; Kamarianakis, Y.; Stanislawski, M. Validation of ASTER GDEM for the area of Greece. Photogramm. Eng. Remote Sens. 2011, 77, 157-166. [CrossRef]

11. Gleyzes, J.P.; Meygret, A.; Fratter, C.; Panem, C.; Ballarin, S.; Valorge, C. SPOT5-System overview and image ground segment. In Proceedings of the IGARSS, Toulouse, France, 21-25 July 2003.

12. Gleyzes, M.A.; Perret, L.; Kubik, P. Pleiades system architecture and main performances. Int. Arch. Photogramm. Remote Sens. Spat. Inf. Sci. 2012, 39, B1. [CrossRef]

13. Poli, D.; Remondino, F.; Angiuli, E.; Agugiaro, G. Radiometric and geometric evaluation of GeoEye-1, WorldView-2 and Pléiades-1A stereo images for 3D information extraction. ISPRS J. Photogramm. Remote Sens. 2015, 100, $35-47$. [CrossRef]

14. Perko, R.; Raggam, H.; Gutjahr, K.H.; Schardt, M. Advanced DTM generation from Very High-Resolution Satellite stereo images. ISPRS Ann. Photogramm. Remote Sens. Spat. Inf. Sci. 2015, II-3/W4, 165-172. [CrossRef]

15. Berthier, E.; Vincent, C.; Magnússon, E.; Gunnlaugsson, Á.P.; Pitte, P.; Le Meur, E.; Masiokas, M.; Ruiz, L.; Pálsson, F.; Belart, J.M.C.; et al. Glacier topography and elevation changes derived from Pléiades sub-meter stereo images. Cryosphere 2014, 8, 2275-2291. [CrossRef]

16. Centre National d'EtudesSpatiales (. 2016. Available online: https:// pleiades.cnes.fr/en/PLEIADES/index. htm (accessed on 10 March 2018).

17. Nikolakopoulos, K.G.; Kamaratakis, E.K.; Chrysoulakis, N. SRTM vs ASTER elevation products. Comparison for two regions in Crete, Greece. Int. J. Remote Sens. 2006, 27, 4819-4838. [CrossRef]

18. De Lussy, F.; Greslou, D.; Dechoz, C.; Amberg, V.; Delvit, J.M.; Lebegue, L.; Blanchet, G.; Fourest, S. Pleiades HR in flight geometrical calibration: Location and mapping of the focal plane. ISPRS Int. Arch. Photogramm. Remote Sens. Spat. Inf. Sci. 2012, 39. [CrossRef]

19. Eisank, C.; Rieg, L.; Klug, C.; Kleindienst, H.; Sailer, R. Semi-Global Matching of Pléiades tri-stereo imagery to generate detailed digital topography for high-alpine regions. J. Geogr. Inf. Sci. 2015, 2015, 168-177. [CrossRef] 
20. Poursanidis, D.; Chrysoulakis, N. Remote Sensing, natural hazards and the contribution of ESA Sentinels missions. Remote Sens. Appl. Soc. Environ. 2017, 6, 25-38. [CrossRef]

21. Poursanidis, D.; Chrysoulakis, N.; Mitraka, Z. Landsat 8 vs. Landsat 5: A comparison based on urban and peri-urban land cover mapping. Int. J. Appl. Earth Obs. Geoinf. 2015, 35, 259-269. [CrossRef]

22. Grigillo, D.; Kosmatin, M.F.; Petrovič, D. Automated building extraction from IKONOS images in suburban areas. Int. J. Remote Sens. 2012, 33, 5149-5170. [CrossRef]

23. Hongjian, Y.; Shukai, L. Building extraction from DSM acquired by airborne 3D image. Geo-Spat. Inf. Sci. 2012, 6, 25-31. [CrossRef]

24. Dalla, M.; Nex, M.; Remondino, F.; Zanin, M. Integration of photogrammetric DSM and advanced image analysis for the classification of urban areas. Image Signal Process. Remote Sens. 2012, 8537, 85370U.

25. Salehi, B.; Zhang, Y.; Zhong, M.; Dey, V. A review of the effectiveness of spatial information used in urban land cover classification of VHR imagery. Int. J. GeoInf. 2012, 8, 35-51.

26. Salehi, B.; Zhang, Y.; Zhong, M. Automatic moving vehicle information extraction from single-pass WorldView-2 imagery. IEEE J. Sel. Top. Earth Obs. Remote Sens. 2012, 5, 135-145. [CrossRef]

(C) 2018 by the authors. Licensee MDPI, Basel, Switzerland. This article is an open access article distributed under the terms and conditions of the Creative Commons Attribution (CC BY) license (http://creativecommons.org/licenses/by/4.0/). 